\title{
The Mikhail Prokhorov Foundation
}

\author{
Anna Reshetova
}

Published online: 20 February 2009

(C) The Author(s) 2009. This article is published with open access at Springerlink.com

\begin{abstract}
A concise description of and related activities of the Mikhail Prokhorov Foundation with a special focus on the book publishing and bookselling activities in Russia. The three major programs of the Foundation are described with an emphasis on book publishing and the related Krasnoyarsk Book Culture Fair. A critical analysis of the fiction and non-fiction trade book publishing industry is provided as a context for the activities of the Foundation.
\end{abstract}

Keywords Book culture - Education and public education ·

Krasnoyarsk book culture fair · Krasnoyarsk region · Irina Prokhorova ·

Mikhail Prokhorov Foundation - New European theatre · New writing .

Russian national orchestra - Social poster - Taimyr cactus

contemporary arts festival · TRANSCRIPT . Urals · Yeltsin Foundation

Think globally, act locally... Think locally, act globally...

Two central truths of the XXI century

The Mikhail Prokhorov Foundation is a Russian private charity established in 2004. The Foundation's long-term goal is to promote Russian culture, literature and further its integration into the global context. It carries out nationwide and international activities, as well as local projects in the Urals, Siberia, and the Russian Far East. The Foundation was established by Mikhail Prokhorov, a businessman, President of Onexim Group, Co-chairman of Polyus Gold, and Irina Prokhorova, the editor-in-chief of the New Literary Observer which is the title of the magazine and publishing house.

A. Reshetova ( $ه)$

Mikhail Prokhorov Foundation, 12, Pushkin Street, Norilisk, Russia e-mail: reshetova@prokhorovfund.ru 
Created at a time of rapid transformation and modernization of the country as well as fundamental changes in the world charity system, the Foundation seeks to formulate new strategies and approaches for its activities to meet the challenges of the new century.

First of all, the Foundation's concept is based on a broader notion of culture, its boundaries and social functions. Its main aim is to support and develop horizontal cultural institutions and new forms of cultural self-management, and to promote the emergence of an intellectual elite.

Mikhail Prokhorov describes the Foundation's priority as follows: "We regard culture as a most important social and economic factor that impacts the whole of human life. The root of that influence and of the Foundation's profound impact is creative people with new ideas. Our task is to find these people and help them to take their first steps".

The emergence and maturing of the Russian 'creative class' opens up new prospects for the economic development of the country, enabling the regeneration of old, depressed industrial regions through new cultural industries.

Secondly, the Foundation's work is based on the contemporary notion of 'cultural capital', which does not necessarily coincide with the geographical or administrative capital. In a super-centralized country like Russia the very idea of multiplicity of powerful cultural centers sounds innovative and provocative. The Foundation often claims to be the principle 'supporter of the regions' meaning that it creates opportunities for various remote Russian territories to compete with Moscow in cultural diversity and influence. Thus, the Mikhail Prokhorov Foundation's fundamental concept may be described as a "regional (or local) approach": the Foundation develops individual programs for each of the regions in which it functions, based on their unique historical, economic and cultural development and also tries to revive the lost connections between the outside world and local cultural communities. At present, the Foundation is primarily focused on systematic work in the Krasnoyarsk region-a huge territory in Siberia, ranging from the Norilsk industrial conglomerate in the Arctic to the southern Siberian city of Krasnoyarsk.

The Foundation operates both by supporting project initiatives through open grant competitions and by planning and implementing projects of its own. The Foundation is able to initiate its unique projects by engaging leading experts to develop charitable programs together with top managers for the working teams. In effect, the Foundation functions as a creative workshop, generating innovative ideas and setting new high standards on the one hand, while seeking out and supporting the best initiatives by local organizations and citizens on the other.

\section{The Main Programs and Projects}

The Foundation's various cultural initiatives fall within the following areas:

- Education and public education;

- sports and public health;

- contemporary art. 


\section{Education and Public Education}

The Foundation considers education as its core activity. The most dramatic problems faced by Russia's young civil society stem from an obsolete educational system that has been preserved almost unchanged from the totalitarian past. Highly dogmatic and heavily ideologically, post-Soviet education is in great need of radical modernization and re-evaluation of its basic intellectual and moral values. This is a very painful and time-consuming process of creating a new generation of teachers and experts and gradually replacing the aggressive conservative old guard. The Foundation therefore supports a wide range of programs, projects and competitions designed to make education more effective, which includes major projects such as 'Local Histories' that includes new approaches to studying and teaching history with special emphasis on northern civilizations, 'The Development of Mass Media' that provides support for independent media and teaching programmes for regional culture reporters, training courses for School and University Teachers, support for Gifted Children, and 'Academic Mobility' that provides travel grants for regional undergraduates and post-graduate students.

One of the Foundation's main concerns is to promote the development of book culture - an important and ambitious project that comprises a range of activities described in detail below.

Another important area of activity for the Foundation is Sports and Public Health. In this area, the Foundation gives priority to projects that focus on the involvement of children, teenagers, and young people in sports, training of professional coaches, and modernisation of physical education. Special attention is paid to supporting the children hospices, orphanages and AID clinics. The focus is primarily on art therapy as one of the most important means of rehabilitation.

Finally, the Mikhail Prokhorov Foundation pays special attention to developing and encouraging Initiatives in Contemporary Arts. The central theme in this area is support for theatre and multi-media art projects. The Foundation supports several significant Russian cultural projects with an international dimension. It is the General Partner of Mikhail Pletnev's Russian National Orchestra, Lev Dodin's Maly Drama Theatre-Theatre of Europe, The State Theatre of Nations, and the New European Theatre (NET) Festival. In 2008 the Mikhail Prokhorov Foundation set up an open charitable competition entitled New Theatre to support drama productions in the Urals, Siberia and Russia's Far Eastern regions. This year, the Foundation also supported the Russia Dreams exhibition held as part of Art Basel Miami Beach which is the biggest art fair in the United States. In 2010 the Foundation plans to participate in the Year of Russia in France by organizing and sponsoring the Unknown Siberia Festival. The Festival's title is a metaphor for Russia, which for Europe is, in a certain sense, Siberia.

In addition to the nationwide and international projects the Foundation supports cultural initiatives in Norilsk and Krasnoyarsk. One of the big issues for polar Norilsk is its isolation from the cultural life of Russia, so tour projects are among the Foundation's priorities. The most significant project is the Taimyr Cactus Contemporary Arts Festival-a multicultural event and one of the largest festivals in the country, which has become an integral part of Norilsk cultural life. In the 
framework of another large annual project-the Norilsk Seasons theatre festivalNorilsk hosts many performances from Moscow, St. Petersburg and regional theatres. Another program-Social Poster-was designed to draw attention to topical social issues in Norilsk, while at the same time developing the social poster genre.

\section{Book Culture Support Project}

The major cultural event in Krasnoyarsk city (and perhaps in the region in general) for the last 2 years has been the annual Krasnoyarsk book fair launched and sponsored by the Foundation. The fair's full title is Krasnoyarsk Book Culture Fair, the aim of which is to reassess and restore the role of the book in the contemporary multimedia world, to analyze the book's evolution and transformation as it competes with new types of art and information, and to stimulate the distribution system for high quality literature in Siberia and other remote regions of Russia. As the organizers claim, the Krasnoyarsk book fair has the potential to turn this southern Siberian industrial city into Russia's leading center of book culture. The Foundation's main concern is to attract publishers from the educational and quality literature markets to visit the Book Fair regularly and become its biggest participants as well as promoters.

The Book Fair's extensive cultural program is organized around the three fundamental functions of the book in society:

I. The book as a product: There is a series of events for the professional book community including seminars and master classes for librarians; round tables on book distribution issues, copyright, audio and electronic books; seminars on new printing technologies and other relevant topics for the region and current time frame.

II. The book as art: Exhibitions, installations, reading performances, musical and video programs; seminars and master classes on book design, debates and lectures on book illustration; discussions and presentations on the evolution of the book, revival of the exclusive book, book manuscripts, album genre and other topics related to the annual theme of the Krasnoyarsk Book Culture Fair.

III. The book as a social institution: Debates and round tables on the status of contemporary literature, literary prizes, genre innovations in literature; theatre tours including shows based on books; presentations of popular writers and poets.

In short, the Krasnoyarsk Book Fair strives to bring together all strata of the book world: including publishers and distributors, famous writers and poets, artists and musicians from all over Russia and from abroad. In 2008 more than one hundred book publishers, distributors and printers took part, bringing with them to Krasnoyarsk more than 30 tons of books. The Fair was attended by over 20,000 people in relation to the city of Krasnoyarsk that has a population of approximately 900,000.

The urgent need for this type of charitable activity is driven by the dramatic situation regarding the promotion and distribution of good literature in Russia. The 
Foundation's co-founder, Irina Prokhorova, believes that the non-fiction and especially humanities segments in Russia have been experiencing a systemic decline for a long time, and that the current economic crisis has merely exposed the chronic breakdown in this sphere. Although the total number of titles printed has grown continuously during the past 5-8 years, there has been a steady drop in the share of cultural and quality publications.

One of the reasons for the systemic crisis in the Russian book business is the fact that the existing distribution system completely fails to take into account the specifics of the book as a cultural product. Only the biggest publishing houses have their own distribution networks, but they tend to sell mainly their own publications and what may be termed as a "best sellers" strategy. In many towns bookshops and public libraries are being squeezed out of the center towards the periphery. During the 1990s this trend was partly reversed by a network of tiny private intellectual bookstores' set up in basement premises, but these have now all but disappeared. Furthermore, almost all national newspapers, periodicals and TV channels have virtually sacrificed book review space for the sake of cheap entertainment. Consequently, this has destroyed the institution of cultural analyses and the quality book sector has found itself in a state of informational isolation.

As a result, high-quality fiction and non-fiction have very small print-runs from $1-2,000$ up to a maximum of 5,000 copies and do not reach the readers, despite the great public demand as the book fair has vividly demonstrated. The small independent publishers specializing in so-called 'intellectual literature', which emerged in the early 1990s and proliferated strongly despite all the hardships until about 5 years ago, are now on the brink of total extinction. It would therefore be wrong to blame the public for reading too little. All the public gets is mass-produced literature of dubious quality, while the thinking members of society are turning away from reading in search of new ideas in different intellectual media. This is something that the Russian book community has been discussing for a long time.

In Irina Prokhorova's view, to save high-quality publishing in Russia there needs to be a systemic modernization of the entire book industry, together with substantial and properly targeted investment-both private and public. Above all, there needs to be a clear long-term governmental policy viewing culture as a priority and as a major social institution: a system of incentives must be devised for cultural publications, support of existing and new book shops; skills enhancement for specialists in various segments of the book market; improved professional and financial status for librarians, and much more. These measures will help to preserve the book as the ideal depositary of information and contribution to culture, as something whose significance cannot be overestimated.

One of the good traditions accompanying the Fair is the provision of a special grant by the Founder, Mikhail Prokhorov, to buy all the books on show for Krasnoyarsk's libraries. In 2007, this resulted in a gift of over 20,000 books for the region's 67 centralized library systems. In 2008, the grant was almost doubled in size. The Foundation's support for libraries also includes a grant competition entitled New Role of Libraries in Education, which aims to help Russian library system to modernize its technological resources and professional skills to become the center of a new educational process. 
One more important program run by the Foundation within the Book Culture Support project is to be launched in 2009. Entitled TRANSCRIPT, it aims to promote Russian literature and culture throughout the world and will be managed jointly with the Yeltsin Foundation. The two Russian charitable foundations will thereby make a contribution to restoring Russia's image as a country with long-standing traditions and a dynamic modern culture.

The program consists of two steps. The first one will be implemented by the Mikhail Prokhorov Foundation and will support translation of Russian fiction, poetry and non-fiction worldwide. In 2009 the Foundation will subsidize the rights, translation and, in the case of books on humanities, publication of up to 30 works. In the choice of work, preference will be given to intellectual, experimental and innovative works by contemporary Russian authors, as well as works of classical literature never previously translated and little known outside Russia. Decisions on subsidizing publication of a work and on the type of support to be given will be taken by an independent advisory board of experts.

To participate in the program publishers must submit a completed grant application form together with information about the publisher, a short explanation of the choice of work and the translator's resume. The application form and more information are available on the Foundation's website at: www.prokhorovfund.ru. Application forms and any questions should be sent to: transcript@ prokhorovfund.ru (contact personIrina Moglovets). The program will be launched on January 15, 2009, after which foreign publishes are welcome to submit applications for support.

The second step, to be implemented by the Yeltsin Foundation, aims to award the best literary translations from Russian into English, French, Italian, German and Spanish.

Another future project of the Mikhail Prokhorov Foundation is a new literary prize to support contemporary innovative Russian prose, which will also be launched in 2009. Literary prizes as an institution are still at a very early stage of development in Russia. First, there are not many of them, and secondly, they all follow the same pattern, as the same people initiate them and participate in them as experts. They represent a very narrow aesthetic spectrum of contemporary Russian literature. To broaden the perspectives, the Mikhail Prokhorov Foundation is instituting a new literary prize called New Writing $(\mathrm{NeW})$ which, in contrast to other prizes, aims to make public what always remains unseen. Traditionally when literary prizes are awarded the most important decisions usually take place behind the scenes: what makes the Foundation's new prize distinctive is that this debate will now be public. The jury's discussions about why specific writers have been short-listed and what criteria they used will be held in the presence of journalists and the cultural community. This will create the opportunity to launch a major and serious discussion about contemporary literature.

\section{Achievements}

In 2009, the Mikhail Prokhorov Foundation will celebrate its fifth anniversary. Over the last 5 years the Foundation's budget has increased almost tenfold from 
$\$ 1,000,000$ in 2004 to $\$ 10,000,000$ in 2008 . The total amount spent on charity has exceeded \$15,500,000. Since 2004, the Expert Board has processed 2,260 grant applications, 802 of which have been endorsed. Since its establishment, the Foundation has initiated and implemented 29 projects of its own, most of which continue on an annual basis. The Foundation's 2007 Annual Report was named the best report in the private foundations category of the 2nd Point of Reference competition sponsored by the Russian Public Chamber's Commission for Development of Charity and NGO Legislation.

Open Access This article is distributed under the terms of the Creative Commons Attribution Noncommercial License which permits any noncommercial use, distribution, and reproduction in any medium, provided the original author(s) and source are credited. 